Article ID: $1000-9116(2008) 02-0213-04$

Research Note

\title{
Lowermost mantle shear velocity anisotropy beneath Siberia*
}

\author{
YANG Feng-qin ${ }^{*}$ (杨风琴) LIU Bin(刘 斌) NI Si-dao(倪四道) ZENG Xiang-fang (曾祥方) \\ DAI Zhi-yang(戴志阳) LÜ Yan(吕 彦) \\ School of Earth and Space Science, University of Science and Technology of China, Hefei 230026, China
}

Key words: anisotropy; shear wave splitting; D" region; lowermost mantle; Siberia

CLC number: P315. $3^{+} 1 \quad$ Document code: A

\section{Introduction}

D" layer plays an important role in geodynamic process. And seismological research indicates that D" layer has large scale seismic anisotropy, however, most research concentrated on areas such as Northern Pacific, Central Pacific, Caribbean, Central America, Alaska etc. (Wookey et al, 2005; Garnero and Lay, 2003; Matzel et al, 1996; Pulliam and Sen, 1998), because of the limited distribution of sources and stations. And there is no research record concerning the anisotropy of the lowest mantle beneath Siberia.

Shear wave splitting is usually used in the seismological studies on the anisotropy of D" layer, such as S, ScS and Sdiff (Fouch et al, 2001; Garnero and Lay, 1997; Karato, 1998), but it is difficult to consider the influence of the shallow anisotropy near the sources or stations in the analysis. In general, the source side's anisotropy is negligible for deep events (Thomas et al, 2002), while the SKS splitting are usually employed to correct the effects of the upper mantle on receiver side. However, the influence of anisotropy in crust and the upper mantle can be reduced by travel time difference as much as possible, because ray paths of $\mathrm{ScS}$ and $\mathrm{S}$ are close. In this paper, we use the events in Japan and the records of Germany Regional Seismic Array Network (GRSN, Germany), and employ the travel time differences between $\mathrm{ScS}$ and $\mathrm{S}$ to analyze the lowermost mantle shear velocity anisotropy beneath Siberia.

\section{Data and processing}

We chose five events in Japan as shown in Table 1, with 31 records on GRSN satisfying the requirements. Figure 1a shows the events, stations and the ray paths, and the bounce points cover $60^{\circ} \mathrm{N}$ to $71^{\circ} \mathrm{N}, 75^{\circ} \mathrm{E}$ to $86^{\circ} \mathrm{E}$.

Table 1 Earthquake catalog

\begin{tabular}{|c|c|c|c|c|c|}
\hline $\begin{array}{c}\text { Date (UTC) } \\
\text { a-mo-d }\end{array}$ & $\begin{array}{l}\text { Origin time } \\
\text { h:min:s }\end{array}$ & $\varphi_{\mathrm{N}} /^{\circ}$ & $\lambda_{\mathrm{E}} /^{\circ}$ & Depth/km & Magnitude \\
\hline 2007-03-09 & $03: 22: 42.76$ & 43.22 & 133.53 & 441 & $6.1\left(m_{\mathrm{b}}\right)$ \\
\hline 2006-06-11 & $20: 01: 26.31$ & 33.13 & 131.14 & 139 & $6.3\left(M_{\mathrm{W}}\right)$ \\
\hline $2003-08-31$ & $23: 08: 00.26$ & 43.39 & 132.27 & 481 & $6.2\left(M_{\mathrm{W}}\right)$ \\
\hline $2002-06-28$ & $17: 19: 30.27$ & 43.75 & 130.67 & 566 & $7.3\left(M_{\mathrm{W}}\right)$ \\
\hline 2000-08-19 & $17: 26: 27.94$ & 43.82 & 147.17 & 62 & $6.0\left(m_{\mathrm{b}}\right)$ \\
\hline
\end{tabular}

In the study, simple waveforms with stable radiation pattern of $\mathrm{SH}$, high signal noise ratios and clear peaks of $\mathrm{SH}$ and SV were selected from masses of records. The station-event pairs were limited between $70^{\circ}$ and $83^{\circ}$, in this

\footnotetext{
* Received 2007-11-12; accepted in revised form 2008-01-21.

Foundation item: National Natural Science Foundation of China (40537033 and 40425005).

* Author for correspondence: yfq@mail.ustc.edu.cn
} 
region the travel time difference is sensitive to the anisotropy of D" layer for the ray paths of ScS and S are close in mantle except the D" layer. And for the events whose epicentral distances less than $70^{\circ}$, the bounce points of S are much above the core mantle boundary $(\mathrm{CMB})$, and the ray paths of $\mathrm{S}$ and $\mathrm{ScS}$ have significant discrepancy, also the ScS and $\mathrm{S}$ will be interfered by SKS for the distances larger than $83^{\circ}$.

Before measuring the travel time differences, the data are processed by the following steps: (1) The instrument responses were removed; (2) the components of radial and tangential were separated by rotating the horizontal components to great circle path; (3) the velocity records were integrated to displacements; (4) the waveforms were filtered to improve the SNR (Figure 2), with a band pass between $5 \mathrm{~s}$ and $100 \mathrm{~s}$.

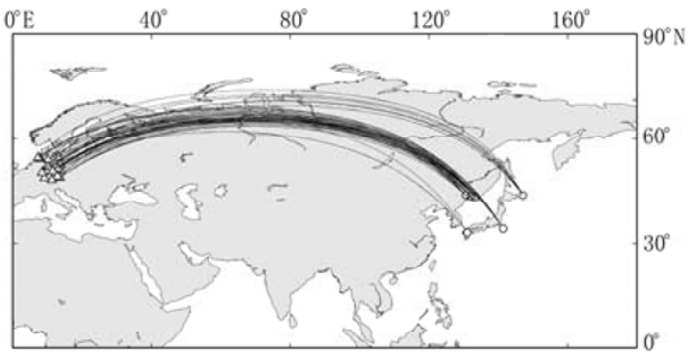

(a)

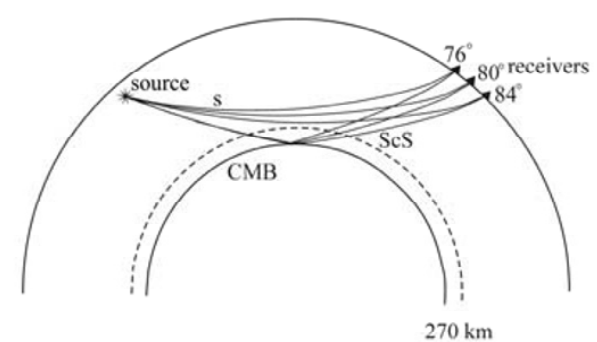

(b)

Figure 1 Distribution of Japan earthquakes (open circles), seismic stations (triangles), and the great circle paths geometry (lines) (a) and ray paths geometry of S and $\mathrm{ScS}$ (b)
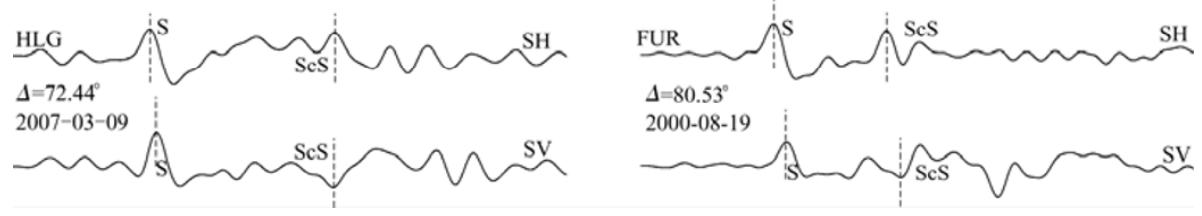

Figure 2 Two waveforms after being processed

HLG and FUR are two recording stations; $\Delta$ stands for epicentral distance. The upper waveform is tangential components, and the lower waveform is radial ones

\section{Method and results}

Travel time differences analysis and the cross correlation are mainly employed in the research of shear wave splitting. DAI et al (2007) compared these two methods, and proposed a formula to calculate the splitting time in D" Layer.

\subsection{Splitting time}

$$
\delta t=\Delta T_{\mathrm{ScSV}-\mathrm{SV}}-\Delta T_{\mathrm{ScSH}-\mathrm{SH}}-0.2
$$

We calculated splitting times of the 31 records with the formula above. We found the values range from $-1.67 \mathrm{~s}$ to $0.35 \mathrm{~s}$, and only two positive values. The average value is $-0.62 \mathrm{~s}$, which means that most of the tangential components travel slower than the radial ones.

\subsection{Anisotropy strength}

Both the splitting time and the strength of anisotropy are important parameters of the anisotropy in lowermost mantle. Ignoring other segments' contributions, we calculated the strength as $\alpha=\delta t / T$. The $\delta t$ is the splitting time measured, while $T$ is the total travel time in D" layer. We adopted the Preliminary Reference Earth Model (PREM) (Dziewonski and Anderson, 1981) model of D" layer with the depth of D" layer ranging from $2641 \mathrm{~km}$ to $2891 \mathrm{~km}$. The travel time was calculated according to PREM model and the anisotropy was assumed homogenous in D" layer. As Figure 4 shows, the results range from $-0.92 \%$ to $0.20 \%$, most of which are between $-0.6 \%$ and $0.0 \%$, and the mean value is $-0.33 \%$. 

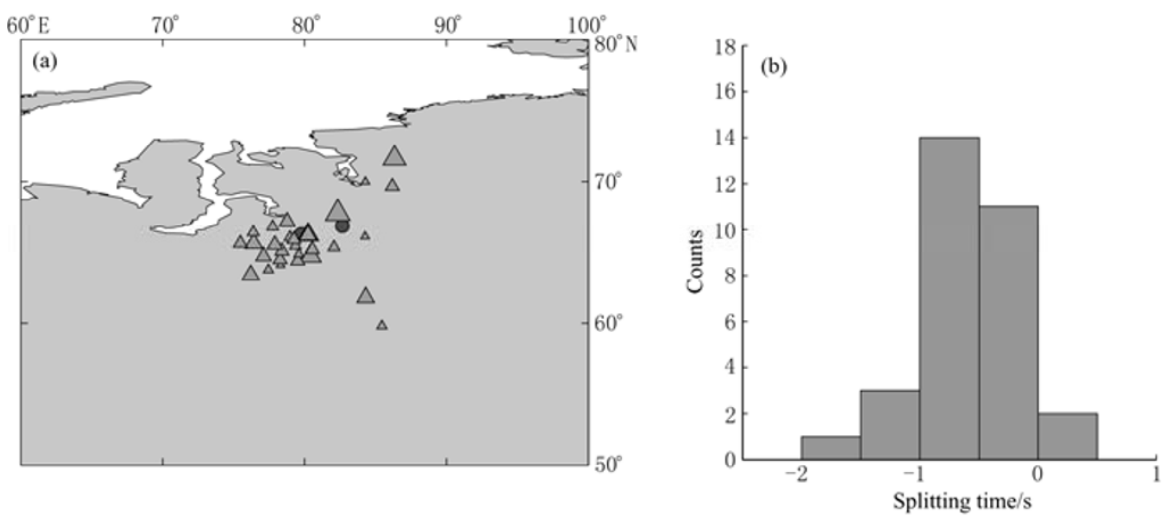

Figure 3 Observations (a) and the histogram (b) of ScS wave splitting time of Japan earthquake The center of mark is the bounce points at CMB, the mark size is proportional to splitting time's magnitude. Triangles indicate the negative splitting time while the circles indicate the positive ones.
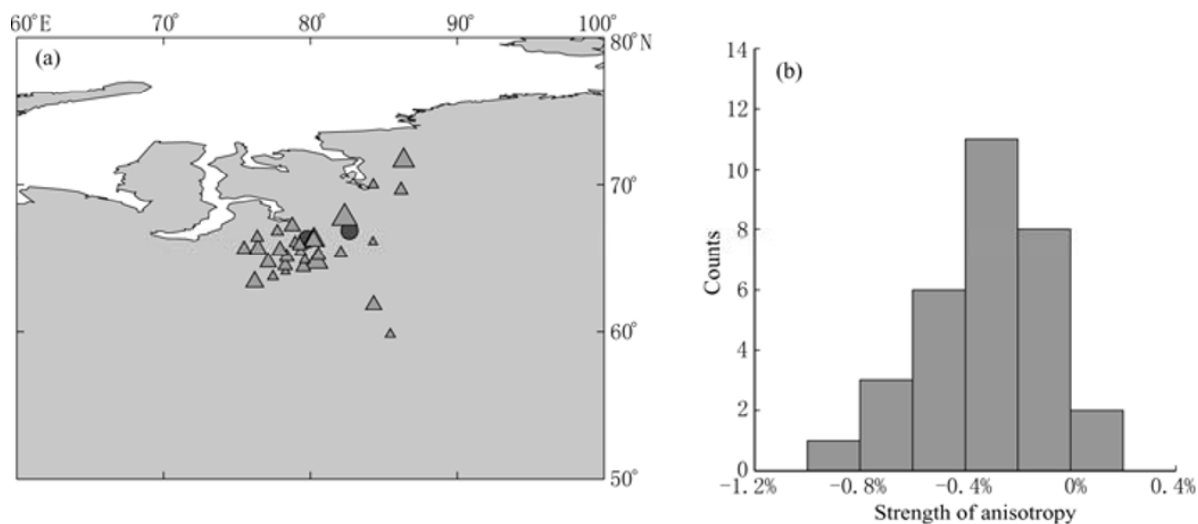

Figure 4 Strength of anisotropy (a) and its histogram (b) of ScS wave splitting time of Japan earthquake Triangle indicates the anisotropy strength corresponding to the negative splitting time while the circles indicate that to the positive one. The mark size is proportional to magnitude of anisotropy's strength.

\section{Mechanism of lowermost mantle anisotropy in Siberia}

Seismologists have investigated anisotropy in D" layer's in many regions. Most results showed that the SH travels faster than SV (Fouch et al, 2001; Wookey et al, 2005; Thomas et al, 2002; DAI et al, 2007), which agrees with the vertical transverse isotropy (VTI) geometry properties. On the contrary, our results demonstrated that the $\mathrm{SV}$ is faster than SH, which is caused by the horizontal transverse isotropy (HTI) (Pulliam and Sen, 1998). In our observations, seismic wave propagated along E-W direction, which illustrates that the geometry structure beneath Siberia has a symmetry axis paralleled to N-S direction.

There are two possible mechanisms of HTI. One is the lattice-preferred orientation (LPO) of anisotropic materials. The other is the shape-preferred orientation (SPO) of material with large velocity anomaly (Pulliam and Sen, 1998).

The observations can be well explained with HTI caused by SPO. Strong vertical shear upwelling in boundary region can result in vertical alignment of the chemically distinct or nonuniform-melted material, which will display as HTI structure. These materials might be the potential products of a core-mantle reaction or the partial melted materials above the CMB (Pulliam and Sen, 1998).

Another alternative explanation is the LPO. The material which has LPO property is the main potential mineral, such as $[\mathrm{Mg}, \mathrm{Fe}] \mathrm{O},[\mathrm{Mg}, \mathrm{Fe}] \mathrm{O}$ is cubic crystal, and its anisotropy varies with azimuth, which may cause $v_{\mathrm{SV}}>v_{\mathrm{SH}}$ in lower mantle (Maupin et al, 2005). The $[\mathrm{Mg}, \mathrm{Fe}] \mathrm{SiO} 3$ post-perovskite is another candidate, which 
shows strong shear wave anisotropy in tri-axial stress field. $v_{\mathrm{SV}}$ is larger than $v_{\mathrm{SH}}$ when [010] paralleled to horizontal, taking agreement with our observation(ZHANG et al, 2007; Karato, 1998).

\section{Conclusions}

The differential travel times of qualified records were used to study the shear wave anisotropy of the D" layer beneath Siberia. Most of the observations acted as $v_{\mathrm{SV}}>v_{\mathrm{SH}}$. The splitting time ranged from $-1.67 \mathrm{~s}$ to $0.35 \mathrm{~s}$, and the mean value was $-0.62 \mathrm{~s}$. The most strength of anisotropy was $-0.92 \%$, while the mean value was $-0.33 \%$. Their distributions had similar trends.

Our observation indicated that the HTI is the dominant structure beneath Siberia. And there are two possible mechanisms of HTI. One is the lattice-preferred orientation (LPO) of anisotropic materials. The other is the shape-preferred orientation (SPO) of material caused by strong upwelling from CMB.

\section{References}

DAI Zhi-yang, LIU Bin, WANG Xiao-xiang, et al. 2007 Shear wave anisotropy in D" region beneath the Western Pacific [J]. Acta Seismologica Sinica, 20(5): 489-496.

Dziewonski A M and Anderson D L. 1981. Preliminary reference Earth model [J]. Phys Earth Planet Inter, 101: 297-356.

Fouch M J, Fischer K M, Wysession M E. 2001. Lowermost mantle anisotropy beneath the Pacific: Imaging the source of the Hawaiian plume [J]. Earth Planet Sci Lett, 190: 167-180.

Garnero E J and Lay T. 1997. Lateral variations in lowermost mantle shear wave anisotropy beneath the north Pacific and Alaska [J]. $J$ Geophys Res, 102: 8 121-8 135.

Garnero E J and Lay T. 2003. D" shear velocity heterogeneity, anisotropy and discontinuity structure beneath the Caribbean and Central America [J]. Phys Earth Planet Inter, 140: 219-242.

Karato Shun-ichiro. 1998. Some remarks on the origin of seismic anisotropy in the D" layer [J]. Earth Planets Space, 50: $1019-1$ 028.

Matzel E. 1996. Evidence for anisotropy in the deep mantle beneath Alaska [J]. Geophys Res Lett, 23(18): $2417-2420$.

Maupin V, Garnero E J, Lay T, et al. 2005. Azimuthal anisotropy in the D" layer beneath the Caribbean [J]. J Geophys Res, 110: B08301, doi:10.1029/2004JB003506.

Pulliam J and Sen M K. 1998. Seismic anisotropy in the core-mantle transition zone [J]. Geophys J Int, 135: 113-128.

Thomas C, Heesom T, Kendall J-M. 2002. Investigating the heterogeneity of the D" region beneath the northern Pacific using a seismic array [J]. J Geophys Res, 107, doi: 10.1029/2000JB000021.

Wookey J, Kendall J-M, Rumpker G.. 2005. Lowermost mantle anisotropy beneath the north Pacific from differential S-ScS splitting [J]. Geophys J Int, 161: 829-838.

ZHANG Hu, LIU Bin, YANG Li, et al. 2007. First principle simulation of MgSiO3 post-perovskite in triaxial stress field and geophysical application [J]. Journal of University of Science and Technology of China, 37(8): 922-926 (in Chinese). 